\title{
Erosion, Corrosion and Erosion-Corrosion of EB PVD Thermal Barrier Coatings
}

\author{
R.G Wellman and J.R Nicholls \\ School of Industrial and Manufacturing Science \\ Cranfield University, Bedford, \\ MK 43 OAL, UK.
}

\begin{abstract}
Electron beam (EB) physical vapour deposited (PVD) thermal barrier coatings (TBCs) have been used in gas turbine engines for a number of years. The primary mode of failure is attributed to oxidation of the bondcoat and growth of the thermally grown oxide (TGO), the alumina scale that forms on the bondcoat and to which the ceramic top coat adheres. Once the TGO reaches a critical thickness the TBC tends to spall and expose the underlying substrate to the hot gases. Erosion is commonly accepted as a secondary failure mechanism, which thins the TBC thus reducing its insulation capability and increasing the TGO growth rate. In severe conditions erosion can completely remove the TBC over time, again resulting in the exposure of the substrate, typically Ni based superalloys. Since engine efficiency is related to turbine entry temperature (TET) there is a constant driving force to increase this temperature. With this drive for higher TETs comes corrosion problems for the yttria stabilised zirconia (YSZ) ceramic topcoat. YSZ is susceptible to attack from molten calcium magnesium alumina silicates (CMAS) which degrades the YSZ both chemically and micro-structurally. CMAS has a melting point of around $1240^{\circ} \mathrm{C}$ and since it is common in atmospheric dust it is easily deposited onto gas turbine blades. If the CMAS then melts and penetrates into the ceramic, the life of the TBC can be significantly reduced. This paper discusses the various failure mechanisms associated with the erosion, corrosion and erosion-corrosion of EB-PVD thermal barrier coatings. The concept of a dimensionless ratio D/d, where $\mathrm{D}$ is the contact footprint diameter and $\mathrm{d}$ is the column diameter, as a means of determining the erosion mechanism is introduced and discussed for EB PVD TBCs.
\end{abstract}

\section{$1 \quad$ Introduction}

The use of thermal barrier coatings (TBCs), which can reduce the metal surface temperature by up to $150^{\circ} \mathrm{C}[1,2]$, in gas turbine engines has resulted in a significant increase in turbine entry temperature resulting in more fuel efficient engines. TBCs have been continually developed and the subject of numerous research papers since they were first tested on turbine blades 30 years ago [3], although Pratt and Whitney were using MgO stabilised zirconia TBCs on burner cans in 1963 [4]. In these early days of TBC use they were generally applied to static gas turbine components by plasma spraying and by the 1980's 7wt\% YSZ emerged as the industry standard ceramic top coat for TBC systems [4]. In the late 1980's electron beam physical vapour deposition techniques were being used to deposit the top coat onto rotating blades. This deposition method resulted in a columnar microstructure which imparted a high degree of strain tolerance making them ideal for applications involving frequent thermal cycles $[4,5]$.

During the early years of TBC use in gas turbine engines oxidation of the bond coat was typically accepted as the primary cause of failure, and has thus been extensively researched, specifically issues associated with thermal cycling of the TBC [6-9]. Erosion of TBCs while acknowledged as a problem $[10,11]$ has until recently been considered a secondary problem, however with the use of EB PVD TBCs on turbine blades erosion has become more of an issue and has received more attention with numerous papers covering the topic of TBC erosion. Early work concentrated on the effect of variables like velocity, impact angle and erodent properties [12-15], while more recent work has examined erosion mechanisms [16-18] and the effects of aging and dopent additions [19]. 
However, as the ceramic top coat and the processing have developed the temperatures at which TBCs have operated has increased significantly resulting in oxidation issues with the bond coat and more recently, with the surface of the $\mathrm{TBC}$ reaching temperatures greater than $1240^{\circ} \mathrm{C}, \mathrm{CMAS}$ attack. CMAS, or calcium magnesium alumina silicates, is a low melting point flux which can form deposits on the surface of the TBC. When the surface temperature is greater than $1240^{\circ} \mathrm{C}$, the CMAS melting temperature [20] CMAS will infiltrate the TBC resulting in extensive degradation of the columnar microstructure and 'locking' the tops of the columns together on cooling resulting in a loss of strain tolerance.

The schematic in Figure 1 illustrates the various degradation mechanisms that can occur to thermal barrier coatings during service in gas turbine engines. During laboratory testing most of these issues are investigated independently, whereas in reality a number of these mechanisms are normally occurring simultaneously. This paper briefly discusses the various degradation mechanisms before examining the interactions between some of the mechanisms specifically CMAS attack and erosion (i.e. erosioncorrosion).

\section{Erosion Mechanisms}

The erosion mechanisms of EB PVD TBCs have been discussed in numerous papers [16-18] the last few years and have been broadly divided into three different mechanisms relating to both the damage morphology and degree of damage caused to the coatings. Briefly, these consist of:

- Erosion - the gradual chipping away of the coating with damage confined to the top $30 \mu \mathrm{m}$ of the coating. This mechanism operates during impact by small particles travelling at high velocities and cracks are initiated in individual columns. A number of neighbouring columns need to be cracked before material is lost from the coating, cracks do not propagate across columns.

- Compaction Damage - the densification of the top of the coating without either cracking or gross deformation of the coating. This is an intermediate transition mechanism between erosion and FOD.

- Foreign Object Damage - the gross deformation of the coating, often through to the bond coat, with associated regions of densification, cracking and kink bands, Type I FOD. Under FOD conditions the contact area is significantly larger than the average column diameter and occurs over a significant number of columns. Under high temperature conditions it is possible for the EB PVD columns to deform plastically in the form of ' $S$ ' bends without the associated cracking and kink band formation, Type II FOD, as a means of adsorbing the impact energy.

These different erosion mechanisms, illustrated in Figure 2, can also be described in terms of the ratio between the contact diameter of the impacting particle and the column diameter. This is a similar principle to the measured decrease in TBC hardness with increasing load [21], which relates to the number of columns with which the indenter interacts as illustrated in Figure 3. This effect is due to the fact that at low loads the indenter is interacting with only one column and hence is measuring the hardness of a single column, however as the load increases the number of columns with which the indenter interacts increases resulting in greater system compliance and hence a lower measured hardness. As the load in increased the point is reached where the system compliance is no longer increasing and the hardness of the coating is being measured.

It was this observation that initially led to the concept of the $\mathbf{D} / \mathbf{d}$ ratio, where $\mathbf{D}$ is the contact footprint diameter and $\mathbf{d}$ is the column diameter. This dimensionless ratio takes into account a number of otherwise difficult to resolve variables, including coating and particle mechanical properties, particle size and particle velocity. The graph in Figure 4 shows that the $\mathbf{D} / \mathbf{d}$ ratio allows one to clearly determine the damage mechanism that is operating under particle impact conditions. Further work needs to be conducted to couple the $\mathrm{D} / \mathrm{d}$ ratio with the strain rate in order to generate a new type of erosion map. As 
can be seen from the graph in Figure 4 a D/d ratio of less than 2 indicates an erosion mechanism, while a ratio of 2-12 indicates a compaction mechanism and greater than 12 a foreign object damage mechanism. For the measured results so far it appears as though this ratio is independent of temperature.

Recently Steenbakker et al [22] identified a new erosion mechanism while examining the effects of gadolinia additions on the erosion of EB PVD TBCs, where, due to the effect of the extremely narrow columns, $3-5 \mu \mathrm{m}$ diameter, the coating behaved more as a continuum than as a discreet columns. As can be seen in Figure 5a lateral cracks appear to propagate across the column boundaries without any difficulty. However, under the high temperature $\left(825^{\circ} \mathrm{C}\right)$ test conditions the erosion mechanism changed to a FOD mechanism, as illustrated in Figure 5b, with the associated cracking and kink bands. This change in mechanism was partly attributed to the increase in velocity of the $825^{\circ} \mathrm{C}$ tests over the room temperature tests and the associated increase in contact area, further illustrating the effect of the $\mathbf{D} / \mathbf{d}$ ratio on the erosion of EB PVD TBCs.

The dimensionless ratio $\mathbf{D} / \mathbf{d}$ has a number of advantages in determining the erosion regime for EB PVD TBCs and if coupled with strain rates during impact could be used to generate useful erosion maps. The column diameter of EB PVD TBCs is fairly standard for a given deposition process and can also be easily measured. While the contact footprint diameter includes a large number of important variables into one parameter, these variables include particle velocity, density size and mechanical properties as well as the mechanical properties of the EB PVD TBC. Although more difficult to measure than the column diameter, the contact footprint diameter can be calculated to a first approximation using Hertzian contact principles [16].

\section{Corrosion (CMAS Attack)}

Until recently the maximum surface temperatures of TBCs during peak operation conditions was lower than $1240^{\circ} \mathrm{C}$ and hence attack of the TBC by molten CMAS (calcium-magnesium-alumina-silicates) was not an issue. However, as the drive to more efficient engines continues and the reliability and performance of EB PVD TBCs improves, TBC surface temperatures of $1240^{\circ} \mathrm{C}$ and greater can occur during normal operating conditions. This is the temperature at which CMAS melts and, as it has excellent wetting properties, it can easily penetrate into the structure of the TBC. Since the TBC is in a thermal gradient the depth of penetration of the CMAS is limited to the point at which the TBC temperature is equal to the melting temperature of the CMAS. The SEM micrograph in Figure 6 shows how CMAS attack causes degradation of the TBC columnar microstructure.

CMAS attack not only degrades the columnar microstructure but also the crystal structure and resulted in a transformation from the metastable tetragonal phase ( $\left.\mathrm{t}^{\prime}\right)$ to monoclinic $(\mathrm{m})$ after only $24 \mathrm{hrs}$ at $1500^{\circ} \mathrm{C}$ as illustrated by the Raman spectra in Figure 7 an effect that has been noted by other researchers in the literature [23]. However, this chemical attack is not the only problem associated with CMAS damage of EB PVD TBCs, delamination of the regions infiltrated by the CMAS via a cold shock mechanism can cause significant and rapid loss of the TBC [20]. Upon cooling of the TBC to below $1240^{\circ} \mathrm{C}$ the CMAS will solidify and 'lock' the infiltrated columns together thus affecting the strain tolerance of the TBC. During shut down of the engine with its associated rapid cooling of the TBC high stresses will develop in the surface region which can initiate cracking parallel to the surface of the TBC. Future engine cycles will result in the spallation of the TBC exposing 'fresh' TBC to CMAS attack. This mechanism can result in the rapid loss of the TBC in regions subjected to CMAS attack. Furthermore, depending on the degree of penetration of the CMAS into the coating, the effect of particle impact on rate of material loss can vary significantly as discussed in the following section under erosion corrosion. 
One of the fundamental points about the erosion of EB PVD TBCs is that cracks, initiated by particle impact in the erosion regime, do not propagate across the column boundaries, which accounts for their relatively low erosion rate. However, under erosion conditions, once the column has cracked material is then relatively easily removed from the surface once a number of its nearest neighbours have also been cracked ${ }^{24}$. It has been shown [19] that sintering of the columns results in an increase in the erosion rate of EB PVD TBCs due to the fact that cracks can propagate into neighboring columns resulting in a greater material loss per impact. The graph in Figure 8 shows that even though the sample that suffered from CMAS degradation was aged for $24 \mathrm{hrs}$ at $1500^{\circ} \mathrm{C}$ its erosion rate was marginally lower than that of the standard TBC, while other samples aged for $24 \mathrm{hrs}$ at $1500^{\circ} \mathrm{C}$ in the absence of CMAS showed a significant increase in erosion rate due to sintering effects.

In the same way that metals show various different responses to particle impact under erosion corrosion conditions, which is dependent on both the thickness of the oxide relative to the depth of damage caused by the impact, resulting in different erosion-corrosion or erosion oxidation regimes [25-28], the response of TBCs to impact will depend on the depth of CMAS penetration relative to the depth of damage caused by an impacting particle. When the CMAS has penetrated into the whole coating as shown in Figure 6 a 'corrosion dominated' erosion regime will prevail. In this case the erosion properties of the CMAS infiltrated TBC will determine the rate of material removal, which under room temperature erosion conditions is slightly lower than a standard EB PVD TBC, as illustrated in Figure 8. This is attributed to the fact that the infiltrated CMAS has solidified and that the system is now behaving as a continuum and cracks initiated in the surface propagate as in a solid and since there are no free edges material is only lost when these cracks intersect with the surface. This is illustrated in Figure 9 where a high degree of cracking can be seen in the near surface region and the associated formation of long lateral cracks.

On the other hand if instead of infiltrating the whole coating the CMAS only penetrates a small degree into the coating (in the region of $30 \mu \mathrm{m}$ ), as would be expected in an operational environment due to the thermal gradient, it is likely that a 'corrosion modified' regime will operate. This is when the impact depth is of a similar size to the depth of CMAS penetration (oxide thickness in metals). Such studies have yet to be performed, however, it is expected that in such a situation the impacting particles would initiate cracks in the TBC parallel to the surface thus facilitating the cold shock mechanism and accelerating the rate of TBC degradation. If however the CMAS penetration was only a few microns into the surface of the TBC it is likely that a different mechanism will operate, 'corrosion enhanced' erosion, which would accelerate the rate of material loss.

Since, under normal operating conditions, particle flux in an engine is low, the erosion rate is also low. Thus even on a long flight erosion-corrosion rates will not be high and it is thus the frequency of engine cycling which becomes important making the cold shock mechanism described in section 3 the dominant degradation mechanism. For CMAS erosion the D/d ratio could still be an effective means of determining the erosion regime except that $\mathbf{d}$ would have to equate to the depth of CMAS penetration. These mechanisms will be highly dependent on the surface temperature of the TBC, however since CMAS infiltration is only likely to occur during peak operation of the engine, i.e. take off, it is reasonable to assume that under 'normal' cruising conditions the CMAS solidifies.

\section{Conclusions}

It has been shown that the $\mathbf{D} / \mathbf{d}$ ratio can be used to determine the erosion regime for EB PVD TBCs:

- A ratio less than 2 indicates an erosion mechanism with near surface cracking. 
- A ratio of between 2 and 12 indicates a compaction damage mechanism.

- A ratio of greater than 12 indicates a FOD damage mechanism with the associated regions of compaction damage near the surface and kink bands that can propagate to the interface.

CMAS attack has been shown to degrade EB PVD TBC via a number of different mechanisms:

- Degrades the columnar microstructure.

- Facilitates the t' to monoclinic phase transformation.

- On cooling the system to below the CMAS melting point the TBC loses its strain tolerance and becomes susceptible to a cold shock delamination degradation mechanism.

However, the current study has also shown that under conditions of total CMAS penetration into the coating the erosion rate is slightly lower than that for as received EB PVD TBCs due to the fact that the system behaves more like a continuum than discreet columns. In order to fully understand the effects of CMAS on the erosion resistance of EB PVD TBCs it will be necessary to examine the effects of the depth of penetration and temperature on the erosion resistance, a program of work is currently being developed to assess these issues.

\section{Reference List}

1. G.W Goward. Progress in Coatings for Gas Turbine Airfoils. Surface and Coatings Technology 108-109, 73-79 (1998).

2. M.J Maloney, H.S Achter, and B.K Barkalow. Development of Low Thermal Conductivity Thermal Barrier Coatings. TBC Workshop 1997.

3. R.A Miller. Current Status of Thermal Barrier Coatings-An Overview. Surface and Coatings Technology 30, 1-11 (1987).

4. S Bose and J Demasi-Marcin. Thermal Barrier Coating Experience in the Gas Turbine Engine at Pratt \& Whitney. Thermal Barrier Coatings Workshop NASA Conference Publication 3312 63-78 (1995).

5. R.A Miller. Thermal Barrier Coatings for Aircraft Engines - The Erosion of Protective Coatings. Thermal Barrier Coatings Workshop NASA Conference Publication 3312 17-34 (1995).

6. T.A Cruse, S.E Stewart, and M Ortiz. Thermal Barrier Coating Life Prediction Model Development. Transactions of the ASME 110, 610-616 (1988).

7. B.C Wu, E Chang, S.F Chang, and C.H Chao. Thermal Cyclic Response of Yttria-Stabilised Zirconia/CoNiCrAlY Thermal Barrier Coatings. Thin Solid Films 172, 185-196 (1989).

8. J.H Sun, E Chang, B.C Wu, and C.H Tsai. The Properties and Performance of $\left(\mathrm{ZRO}_{2}-8 \mathrm{wt} \% \mathrm{Y}_{2} \mathrm{O}_{3}\right) /$ $\left(\mathrm{CVD} \mathrm{Al}_{2} \mathrm{O}_{3}\right) /(\mathrm{Ni}-22 \mathrm{wt} \% \mathrm{Cr}-10 \mathrm{wt} \% \mathrm{Al}-1 \mathrm{wt} \% \mathrm{Y})$ Thermal Barrier Coatings. Surface and Coatings Technology 58, 93-99 (1993).

9. D.M Nissley. Thermal Barrier Coating Life Modelling in Aircraft Gas Turbine Engines. Thermal Barrier Coatings Workshop NASA Conference Publication 3312 265-281 (1995).

10. F.C Toriz, A.B Thakker, and S.K Gupta. Flight Service Evaluation of Therma Barrier Coatings by Physical Vapour Deposition at 5200H. Surface and Coatings Technology 39/40, 161-172 (1989).

11. P Morrel and D.S Rickerby. Advantages/Disadvantages of Various TBC Systems as Perceived by the Engine Manufacturer. AGARD Report 823 20-1 (1998).

12. W Tabakoff. Investigation of Coatings at High Temperature for Use in Turbomachinery. Surface and Coatings Technology 30/40, 97-115 (1989).

13. J.R Nicholls, Y Jaslier, and D.S Rickerby. Erosion of EB-PVD Thermal Barrier Coatings. Materials at High Temperature 15, 15-22 (1998).

14. A.G Davis, D.H Boone, and A.V Levy. Erosion of Ceramic Thermal Barrier Coatings. Wear 110, 101-116 (1986).

15. T Rhys-Jones and F.C Toriz. Thermal Barrier Coatings for Turbine Use in Aero Engines. High Temperature Technology 7, 73-81 (1989). 
16. R.G Wellman and J.R Nicholls. Some Observations on the Erosion Mechanism of EB PVD TBCs. Wear 242, 89-96 (2000).

17. R.G Wellman, M.J Deakin, and J.R Nicholls. The Effect of TBC Morphology on the Erosion Rate of EB PVD TBCs. Wear 258, 349-356 (2005).

18. X Chen et al. Mechanisms Governing the High Temperature Erosion of Thermla Barrier Coatings. Wear 256, 735-746 (2004).

19. R.G Wellman and J.R Nicholls. On the Effect of Aging on the Erosion of EB PVD TBCs. Surface and Coatings Technology 177-178, 80-88 (2004).

20. C Mercer, S Faulhaber, a.G Evans, and R Darolia. A Delamination Mechanism for Thermal Barrier Coatings Subjected to Calium-Magnesium-Alumina-Silicate (CMAS) Infiltration. Acta Materialia 53, 1029-1039 (2005).

21. R.G Wellman, A Dyer, and J.R Nicholls. Nano and Micro Indentation Studies of Bulk Zirconia and EB PVD TBCs. Surface and Coatings Technology 176, 253-260 (2004).

22. R.J.L Steenbakker, R.G Wellman, and J.R Nicholls. Erosion of Gadolinia Doped EB PVD TBCs. Surface \& Coatings Technology accepted, (2006).

23. S Kramer, J Yang, and C.G Levi. Thermochemical Interaction of Thermal Barrier Coatings with Molten $\mathrm{CaO}-\mathrm{MgO}-\mathrm{Al}_{2} \mathrm{O}_{3}-\mathrm{SiO}_{2}$ (CMAS) Deposits. Journal of American ceramic Society 89, 31673175 (2006).

24. R.G Wellman and J.R Nicholls. A Monte Carlo Model for Predicting the Erosion Rate of EB PVD TBCs . Wear 256, 889-899 (2004).

25. V.K Sethi and R.G Corey. High Temperature Erosin of Alloys in Oxidising Environments. Proceedings of the 7th International Conference on Erosion by Liquid and Solid Impact. 87.

26. D.M Rishel, F.S Pettit, and N Birks. Spalling Types and Mechanisms in the Erosion-Corrosion of Metals at High Temperature. Corrosion Science 35, 1007-1013 (1993).

27. M.M Stack, J Chacon-Nava, and F.H Stott. Relationship between the Effects of Velocity and Alloy Corrosion Resistance in ERosion-Corrosion Environments at Elervated Temperatures. Wear 180, 91-99 (1995).

28. D.J Stephenson and J.R Nicholls. Modelling the Influence of Surface Oxidation on High Temperature Erosion. Wear 186-187, 284-290 (1995). 


\section{List of Figure Captions}

Figure 1: Schematic illustrating the types of damage that can occur to TBCs in an engine environment.

Figure 2: SEM micrographs illustrating different erosion mechanisms, a) erosion, b) FOD Type I, c) FOD Type II.

Figure 3: Effect of increasing load on the measured hardness of EBPVD TBCs.

Figure 4: Graph of measured D/d ratios for different impact conditions.

Figure 5: SEM micrograph showing erosion of a doped EBPVD TBC, a) at room temperature and b) at high temperature.

Figure 6: SEM micrograph showing CMAS attack of an EB PVD TBC.

Figure 7: Raman Spectra of EB PVD TBC a) before CMAS attack and b) after CMAS attack.

Figure 8: Graph showing the effect of aging on the erosion of EB PVD TBCs ${ }^{19}$ with data added showing the effect of CMAS on the erosion rate of EB PVD TBCs.

Figure 9: SEM micrographs of EB PVD TBCs that have been chemically attacked by CMAS prior to erosion testing, showing impact damage in the form of cracking. 


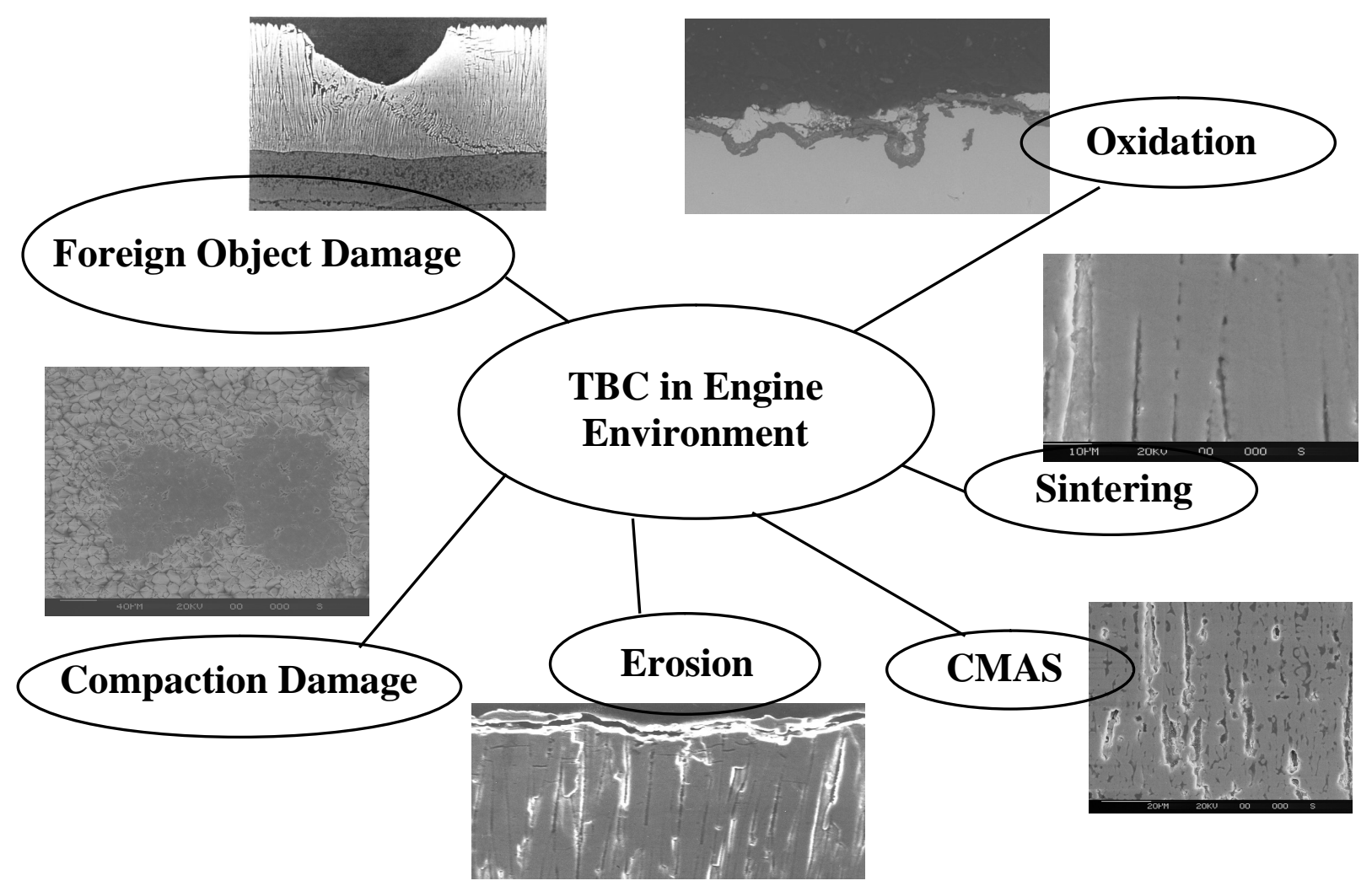

Figure 1: Schematic illustrating the types of damage that can occur to TBCs in an engine environment. 


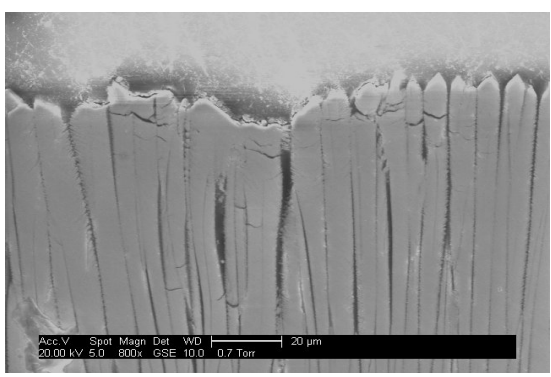

(a)

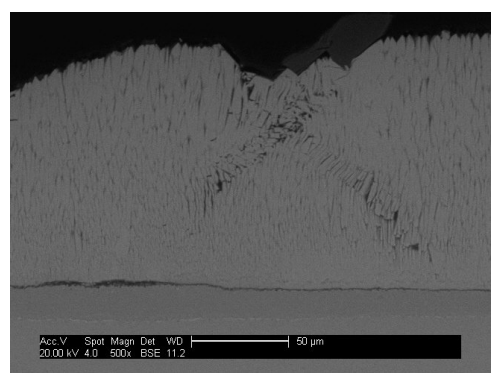

(b)

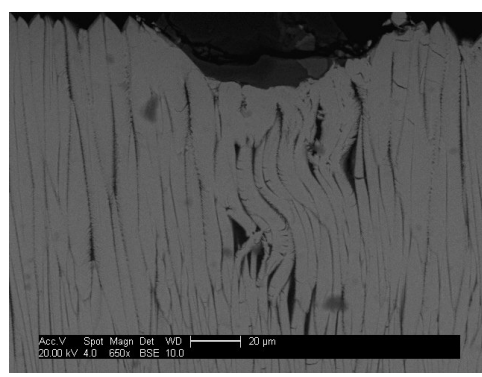

(c)

Figure 2: SEM micrographs illustrating different erosion mechanisms, a) erosion, b) FOD Type I, c) FOD Type II. 


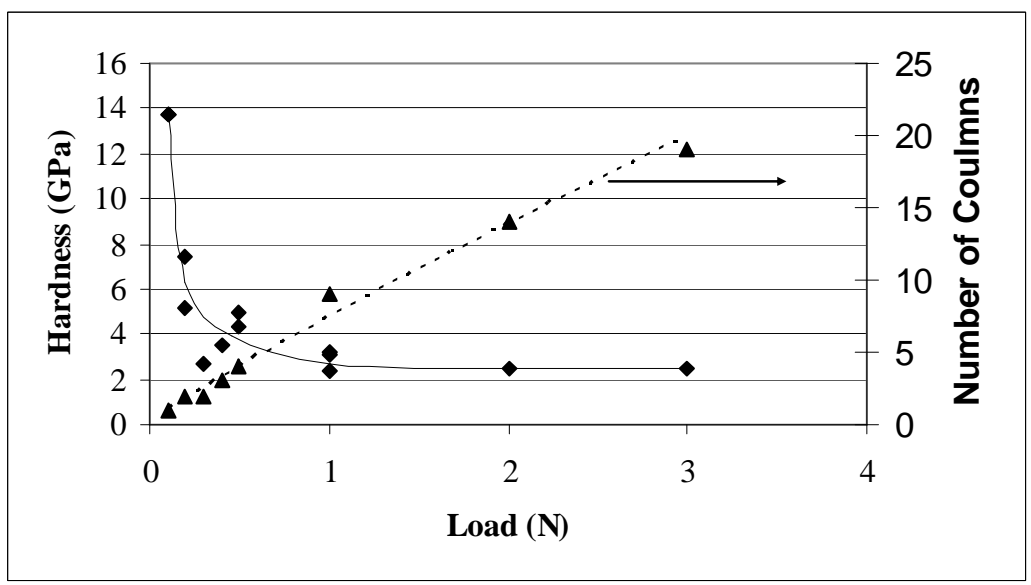

Figure 3: Effect of increasing load on the measured hardness of EBPVD TBCs. 


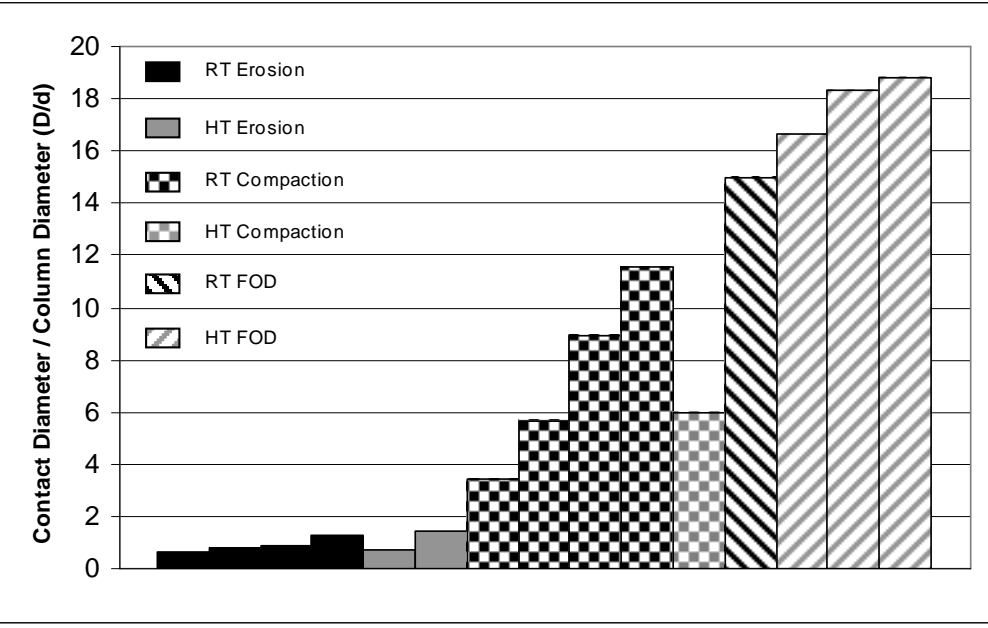

Figure 4: Graph of measured D/d ratios for different impact conditions. 


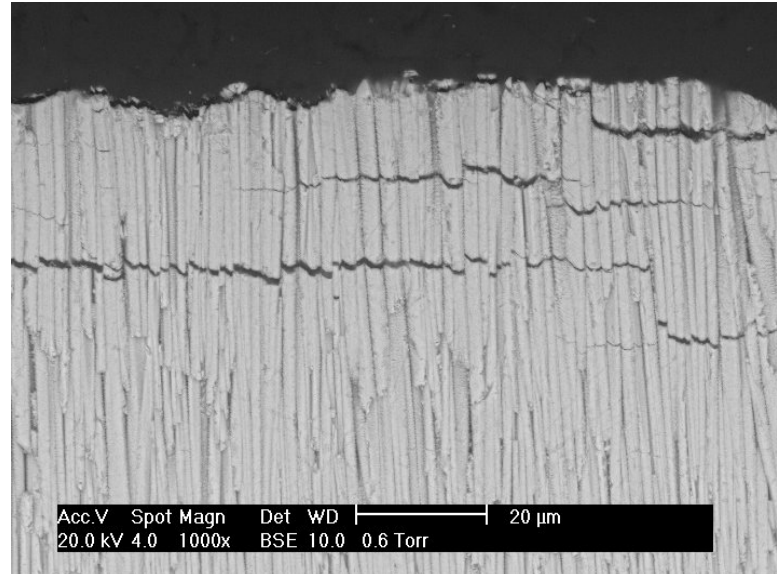

(a)

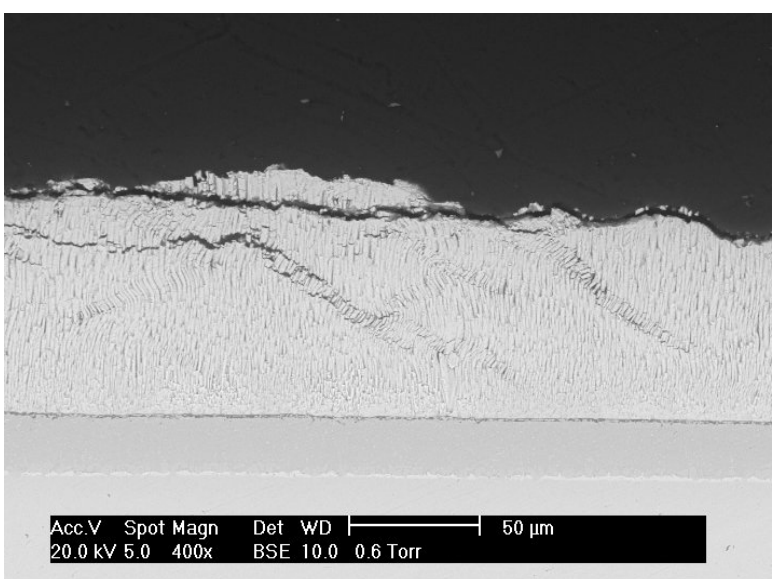

(b)

Figure 5: SEM micrograph showing erosion of a doped EBPVD TBC, a) at room temperature and b) at high temperature. 


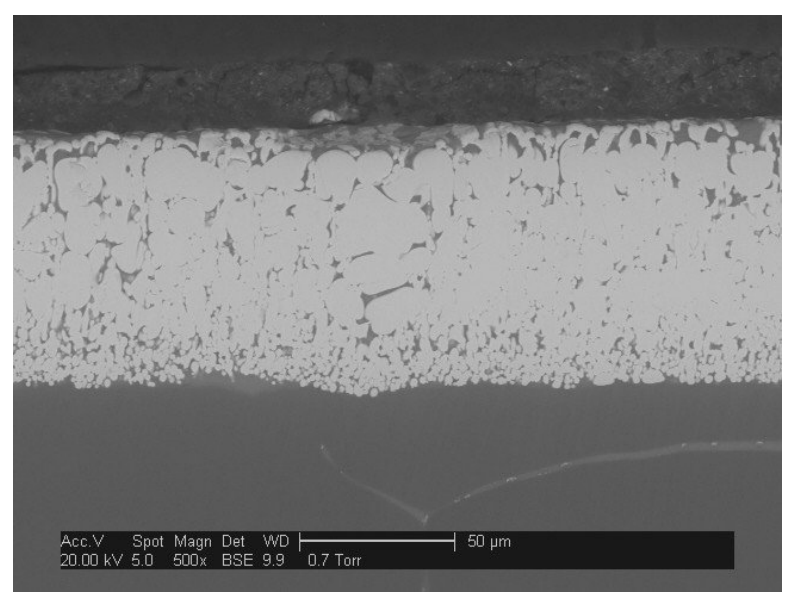

Figure 6: SEM micrograph showing CMAS attack of an EB PVD TBC. 


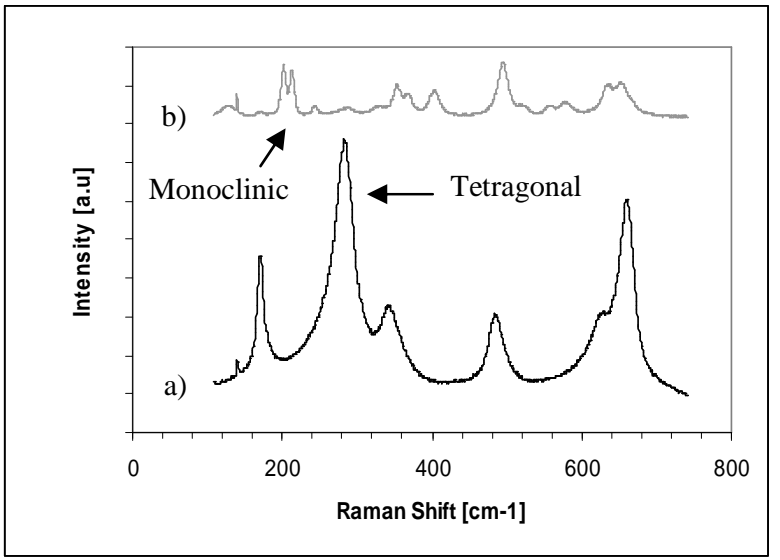

Figure 7: Raman Spectra of EB PVD TBC a) before CMAS attack and b) after CMAS attack. 


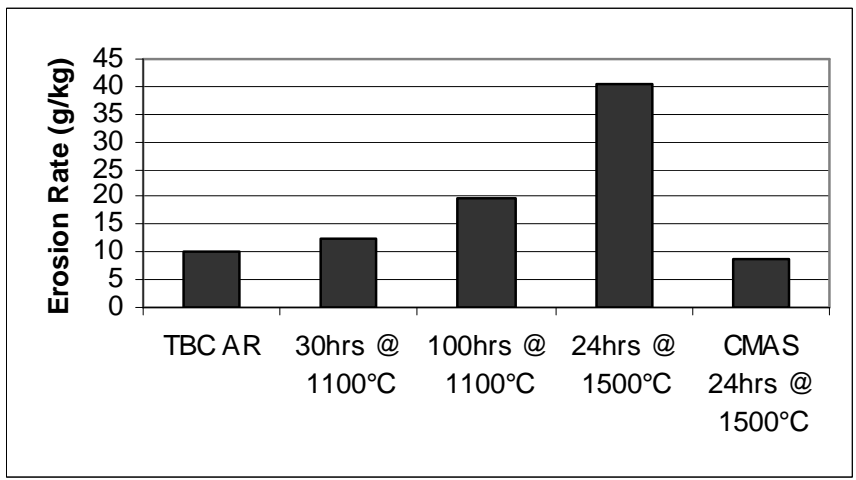

Figure 8: Graph showing the effect of aging on the erosion of EB PVD TBCs ${ }^{19}$ with data added showing the effect of CMAS on the erosion rate of EB PVD TBCs. 

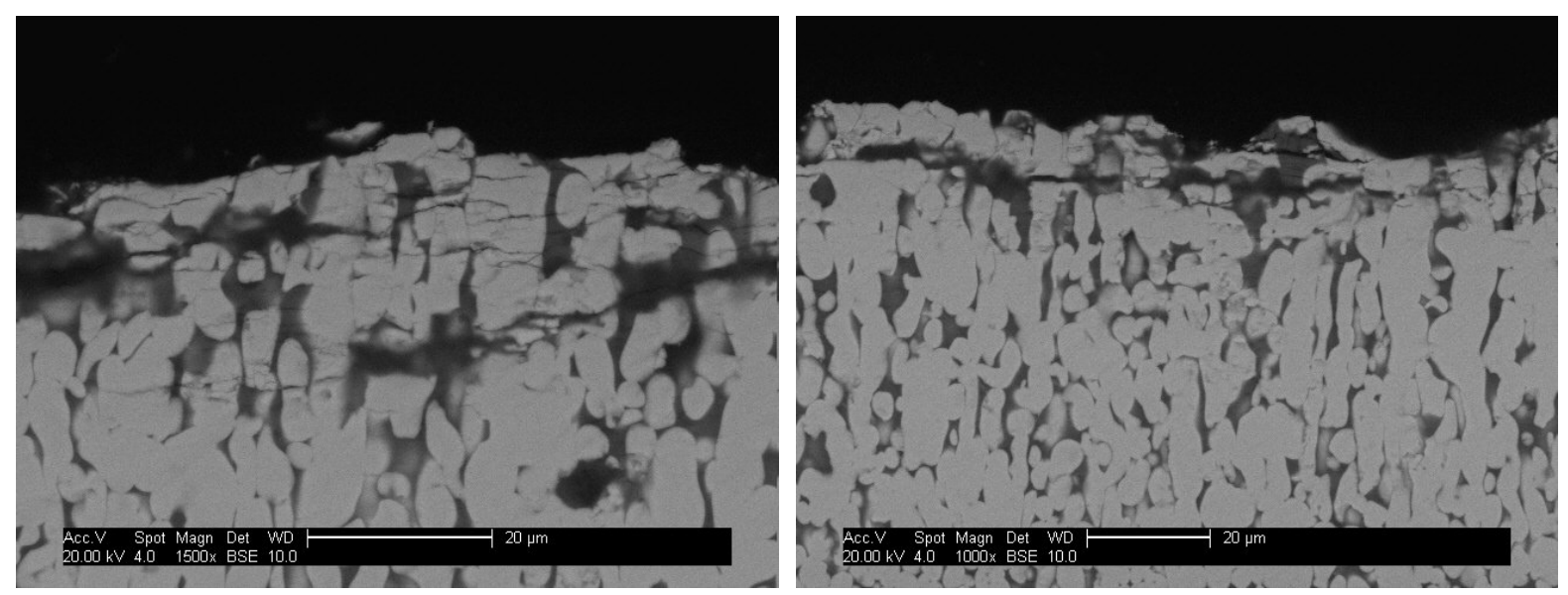

Figure 9: SEM micrographs of EB PVD TBCs that have been chemically attacked by CMAS prior to erosion testing, showing impact damage in the form of cracking. 